\title{
Measurements of unsaturated soil properties of old and new mature fine tailings
}

\author{
L.K. Kabwe Civil and Environmental Engineering, University of Alberta, Canada
}

M. Kone Suncor Energy Inc., Canada

A. Sorta Civil and Environmental Engineering, University of Alberta, Canada

G.W. Wilson Civil and Environmental Engineering, University of Alberta, Canada

J.D. Scott Civil and Environmental Engineering, University of Alberta, Canada

A.C. Ulrich Civil and Environmental Engineering, University of Alberta, Canada

\begin{abstract}
The Geotechnical Centre at the University of Alberta decommissioned two research standpipes in 2012 that had been monitored for 30 years. These $10 \mathrm{~m}$ high standpipes were filled with mature fine tailings (MFT) collected from Syncrude's Mildred Lake tailings pond. Samples were collected from Standpipe 1 prior to decommissioning to determine basic physical properties and unsaturated soil properties of the MFT. A summary of measured soil properties, including soil water characteristic curve (SWCC) and its associated shrinkage curve, are presented. The atmospheric drying of the MFT was compared using the original untreated MFT and three treated fine tailings: flocculated thickened tailings (TT) with 49\% solids content, flocculated TT with 1\% flyash and in-line flocculated (ILF) MFT with 32\% solids content. Results show that the residual bitumen has an effect on the rate of evaporation of MFT with a low solids content. The free bitumen forms a film on the surface of the MFT, which decreases drying from deeper layers and reduces the actual evaporation. The results provide new insights into the atmospheric drying of MFT.
\end{abstract}

\section{Introduction}

Open-water tailings ponds are used to store fine fluid tailings (FFT), which are composed of water, bitumen and fines after oil sands separation and which present long-term liabilities for the oil sands industry. The very slow consolidation behaviour of the FFT is believed to be caused by extensive clay dispersion from the extraction process that dictates the chemical interaction between clay, water and residual bitumen (Jeeravipoolvarn et al., 2009). The need to understand the consolidation behaviour of the FFT resulted in the establishment of long-term large-scale self-weight consolidation tests at the University of Alberta. With the introduction of Directive 074 by the Energy Resources Conservation Board regulatory body, research is under way to find more-effective methods of dewatering to reduce the volume of FFT as well as to increase the shear strength of the deposits by increasing the solids content. Two dewatering methods that have shown considerable promise are in-line flocculated FFT with thin lift deposit and mature fine tailings (MFT) with flocculation and centrifugation. These treated FFTs are then exposed to atmospheric drying (i.e. solar energy and wind) to further dewater them to a stage that permits foot and vehicle traffic on their surfaces. The drying process has been shown to be problematic, even though the surface of the material quickly loses water and dries to a film. It was found that the formation of a crust on the surface of the deposit reduced the rate of actual evaporation (Wilson et al., 2011).

The objectives of this study are to evaluate the dewatering behaviour of fine oil sands tailings by conducting soil water characteristic curve (SWCC) and drying tests on the standpipe MFT samples described below and on the MFT diluted to its original water content, while comparing these with three other fine tailings samples as follows: flocculated thickened tailings (TT) with $49 \%$ solids content, flocculated TT with $1 \%$ flyash and in-line flocculated (ILF) MFT with $32 \%$ solids content. MFT tailings samples that were placed 
in $10 \mathrm{~m}$ standpipes 30 years ago were used in the testing programme to represent the vast deposits of legacy MFT tailings that need to be reclaimed in the future.

\section{$2 \quad$ Materials and methods}

\subsection{Standpipes and MFT}

Two $10 \mathrm{~m}$ standpipes filled with MFT and sand were constructed in 1982. The standpipes (Figure 1) are made of high-density polyethylene with $25 \mathrm{~mm}$ thick walls, with an inside diameter of $914 \mathrm{~mm}$, and are $10.5 \mathrm{~m}$ in height. They were located in a laboratory at the University of Alberta, which has a fairly consistent temperature of around $21^{\circ} \mathrm{C}$. The standpipes were decommissioned in 2012.

Tailings placed in the standpipes were MFT pumped from the centre of Syncrude's Mildred Lake tailings pond from a depth of about $25 \mathrm{~m}$ (Jeeravipoolvarn et al., 2009). The MFT were placed in barrels and transported to the University of Alberta. After thoroughly mixing the MFT in barrels to achieve a uniform material, Standpipe 1, which was investigated in this study, was filled in October 1982 to $10 \mathrm{~m}$ in height with $6.57 \mathrm{~m}^{3}$ of MFT. The properties of MFT placed in Standpipe 1 are shown in Table 1 (Jeeravipoolvarn et al., 2009).

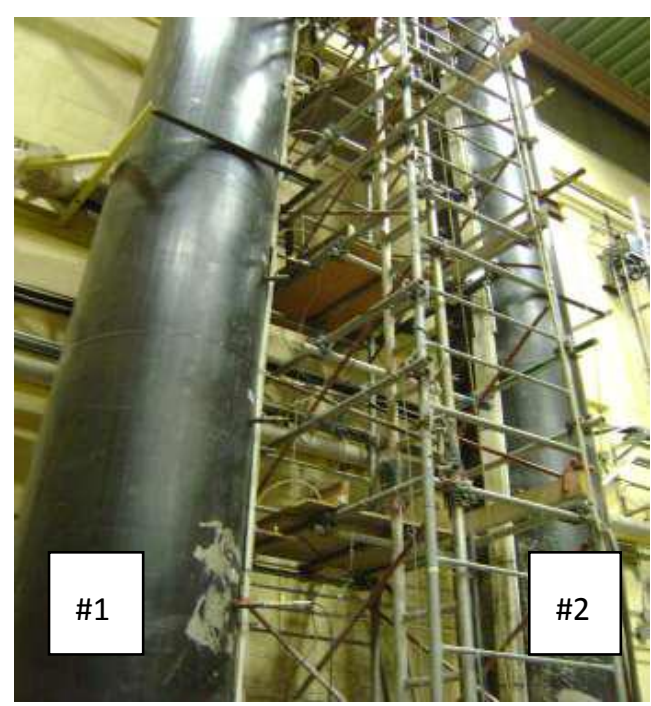

Figure 1 Two $10 \mathrm{~m}$ standpipes at the University of Alberta prior to decommissioning

Table 1 Initial properties of the MFT in Standpipe 1

\begin{tabular}{cc}
\hline Initial solids content (\%) & 30.6 \\
Initial water content (\%) & 226.8 \\
Find content (\% by dry mass) & 89.0 \\
Sand content (\% by dry mass) & 11.0 \\
Bitumen content (\%) & 3.1 \\
Initial bulk density (g/cm ${ }^{3}$ ) & 1.21 \\
Initial void ratio & 5.17 \\
Specific gravity & 2.28 \\
Sand to fine ratio & 0.12 \\
\hline
\end{tabular}




\subsection{Mineralogy}

The mineralogical tests were carried out by AGAT Laboratories Ltd. in Calgary, Alberta, Canada. The dry solid MFT sample was cleansed of hydrocarbons prior to analysis for bulk and clay X-ray diffraction (XRD) mineralogy. The sample was examined using XRD and X-ray energy spectrometry (XES) techniques to determine mineralogical and elemental compositions, respectively. It is important to note that XES does not detect elements with an atomic number smaller than 6 (carbon). In order to separate the particles less than $3 \mu \mathrm{m}$ in size (clay fraction) from the bulk fraction, the sample was treated in an ultrasonic bath using sodium metaphosphate as a deflocculating agent. The material was then centrifuged at different speeds, which separated the clay fraction from the bulk materials. The weight fraction was measured for both the bulk and clay portions of the sample.

\subsection{Bitumen content}

The bitumen content was determined in the MFT sample using a modified Dean Stark method (AGAT Laboratories Ltd). The Dean Stark bitumen removal process requires driving off all the water from the sample as well as removing the bitumen by flushing it with toluene in a modified Stark Extractor.

\subsection{Particle size distribution (PSD) measurements}

Dispersed and non-dispersed hydrometer-sieve tests were conducted on the MFT samples. The objective of the non-dispersed test is to not disperse the clay fraction in the MFT to any greater degree than it is in the standpipes and tailings dam. A modified ASTM Standard Hydrometer-Sieve Test Method was used to measure the PSD of the MFT. The amount of fines $(<45 \mu \mathrm{m})$ was determined by sieving, and the amount of clay-size material $(<2 \mu \mathrm{m})$ was determined by hydrometer.

\subsection{Methylene blue (MB) test}

The methylene blue adsorption value was determined by AGAT Laboratories Ltd. to assess the degree of dispersion of active clays. Methylene blue is a cationic dye that can be adsorbed on the surface of exposed, negatively charged clays and that is routinely used to measure the exposed surface area of clays in soils.

\subsection{Evaporation tests}

The evaporation tests were carried out using two lysimeters that were $180 \mathrm{~mm}$ in diameter and $200 \mathrm{~mm}$ in height. One lysimeter contained distilled water to determine the potential evaporation (PE), and the other lysimeter contained the MFT samples to determine the actual evaporation (AE). The change in mass of each lysimeter was continually monitored to determine the rate of evaporation from the lysimeters. The temperature and relative humidity of the air above the evaporating surfaces were also monitored continuously. The tests were conducted at room temperature in a geotechnical laboratory at the University of Alberta.

\subsection{Soil water characteristic curve}

SWCC was measured using a Tempe cell (Figure 2). The Tempe cell was an acrylic pressure plate device with $500 \mathrm{kPa}(5 \mathrm{bar})$ ceramic high entry disc. Air pressure is applied from the inlet located on top of the chamber cap (Figure 2A). Once air is applied, an outlet located at the base plate underneath the high air entry disk allows the drainage of water from the MFT specimen. The change in water content is measured by weighing the specimen and the cell after equilibrium is reached. The procedure is then repeated at progressively higher values of matric suctions. Once the highest pressure value is applied, the MFT specimen is removed from the cell. The water content corresponding to the highest matric suction is measured by oven-drying the MFT specimen. This water content, together with the previous changes in weight, is used to back-calculate the water contents corresponding to the other suction values. The matric suction is then plotted against their corresponding water contents to give the SWCC. 
The MFT specimen tested was collected at a depth of $7 \mathrm{~m}$ from Standpipe 1 . The water and solids contents measured by oven-drying the specimen were $144 \%$ and $41 \%$, respectively. The MFT specimen at initial high water content was poured in the brass ring (Figure 2B) with the open bottom placed on the high air entry disk inside the Tempe cell chamber.

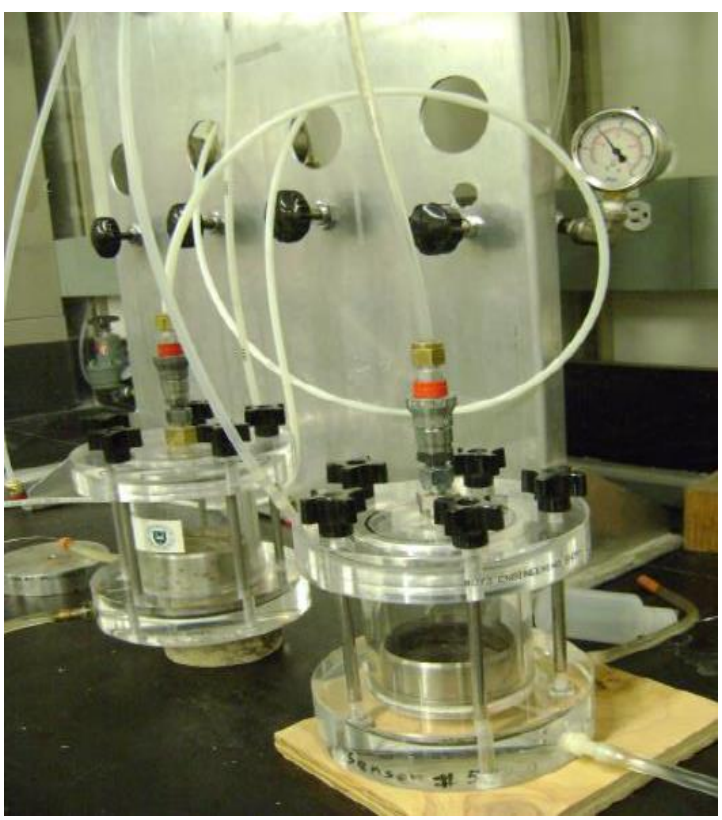

(a)

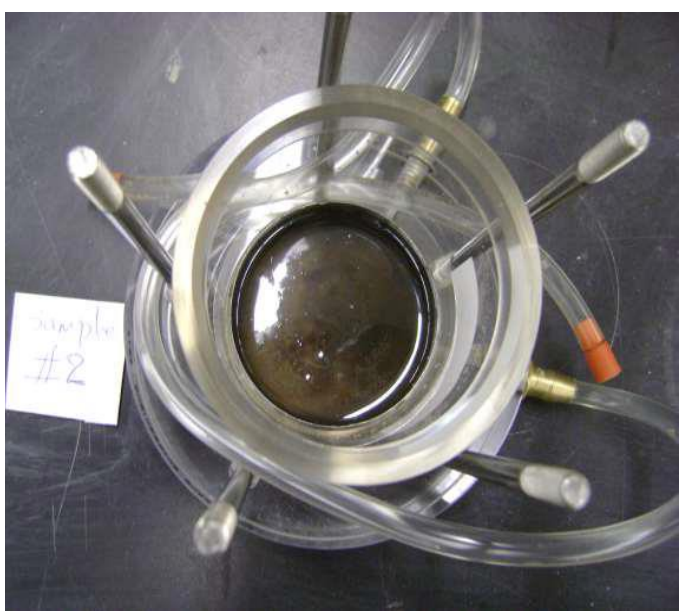

(b)

Figure 2 The Tempe cell setup used for soil water characteristic curve measurement

\section{Results and discussion}

\subsection{MFT slurry basic physical properties}

\subsubsection{Mineralogy}

Table 2 presents the mineralogy of the MFT determined by AGAT Laboratories Ltd.

Table 2 Summary of XRD analysis of MFT determined by AGAT Laboratories Ltd (all values shown as percentages)

\begin{tabular}{|c|c|c|c|c|c|c|c|c|c|}
\hline & & \multicolumn{5}{|c|}{ Rock Forming Minerals } & \multicolumn{3}{|c|}{ Clay Minerals } \\
\hline & & Quartz & $\begin{array}{l}\text { Plagioclase } \\
\text { Feldspar }\end{array}$ & $\begin{array}{l}\text { Potassium } \\
\text { Feldspar }\end{array}$ & Siderite & Total & Kaolinite & Illite & Total \\
\hline & (\%) & (\%) & (\%) & (\%) & (\%) & (\%) & (\%) & (\%) & (\%) \\
\hline $\begin{array}{c}\text { Bulk } \\
\text { fraction }\end{array}$ & 88.34 & 37 & 0 & 2 & 3 & 90 & 36 & 22 & 58 \\
\hline $\begin{array}{c}\text { Clay } \\
\text { fraction }\end{array}$ & 11.66 & 8 & 0 & TR & 1 & 1 & 68 & 23 & 91 \\
\hline $\begin{array}{c}\text { Bulk + } \\
\text { clay }\end{array}$ & 100 & 31 & 0 & 2 & 3 & 0 & 42 & 22 & 64 \\
\hline
\end{tabular}

The combined bulk and clay XRD results (Table 2 ) indicate that the sample consists mainly of kaolinite (42\%) [aluminium silicate hydroxide, $\mathrm{Al}_{4} \mathrm{Si}_{4} \mathrm{O}_{10}(\mathrm{OH})_{8}$ ] and quartz (31\%) [silicon dioxide, $\mathrm{SiO}_{2}$ ], with lesser amounts of illite (22\%) [potassium aluminium silicate hydroxide, $\mathrm{KAl}_{2}\left(\mathrm{AlSi}_{3} \mathrm{O}_{10}\right)(\mathrm{OH})_{2}$ ]. In addition, minor amounts of 
siderite (3\%) [iron carbonate, $\mathrm{FeCO}_{3}$ ] and potassium feldspar (2\%) [potassium aluminium silicate, $\mathrm{K}\left(\mathrm{SiAl}_{3} \mathrm{O}_{8}\right)$ ] were also identified.

The clay fraction $(<3 \mu \mathrm{m})$ weight is $11.66 \%$ of the total solids volume. The clay fraction XRD results (Table 2 ) indicate that the sample consists mainly of kaolinite (68\%), with lesser amounts of illite (23\%) and quartz (8\%). Additionally, minor amounts of siderite (1\%) and potassium feldspar (trace) were also detected.

The XES results indicate that the sample consists mainly of silicon (Si), aluminium (Al) and oxygen (O). Minor amounts of iron (Fe), potassium (K), carbon (C) and sulphur (S), with trace amounts of magnesium (Mg), sodium $(\mathrm{Na})$, calcium $(\mathrm{Ca})$ and titanium $(\mathrm{Ti})$, were also detected.

These analyses indicate that the MFT sample is composed mainly of clays/sands/silts (kaolinite, illite, quartz and potassium feldspar) with minor amounts of iron compounds (siderite and possible amorphous iron sulphur mineral) and of amorphous titanium and with trace calcium, magnesium carbonate and sodium (associated with feldspar).

\subsubsection{Bitumen}

The results of the bitumen analysis using the Dean Stark method (AGAT Laboratories Ltd.) determined the bitumen content to be $2.6 \%$ for the MFT sample collected at a depth of $7 \mathrm{~m}$ depth from Standpipe 1 . This value is close to the initial value of $3.1 \%$ measured from the bulk sample (Table 1). It should be noted that bitumen exists in the tailings as free and adsorbed bitumen. The amount of bitumen is typically greater in finer tailings than coarser tailings. Bitumen that has a specific gravity of about 1.03 is considered part of the fine solids and results in a quite low specific gravity of the total solids compared with other natural clay soils (Jeeravipoolvarn et al., 2009).

\subsubsection{Particle size distribution}

Figure 3 shows both the dispersed and the non-dispersed hydrometer-sieve PSDs of the MFT samples collected at a depth of $7 \mathrm{~m}$ from Standpipe 1 . The amounts of clay-size material $(<2 \mu \mathrm{m})$ determined by hydrometer for the dispersed and non-dispersed tests are $43 \%$ and $25 \%$, respectively. The amounts of siltsize materials $(<75 \mu \mathrm{m})$ determined by hydrometer averaged $53 \%$ and $72 \%$ for the dispersed and nondispersed tests, respectively, with very small amounts of sand size material. The dispersed and nondispersed hydrometer tests show a difference of $18 \%$ in the amount of clay-size material. The nondispersed test should more accurately reflect the particle size distribution of the FFT in the tailings pond. This MFT is mainly silt-clay with a sand-to-fine ratio of about 0.06 .

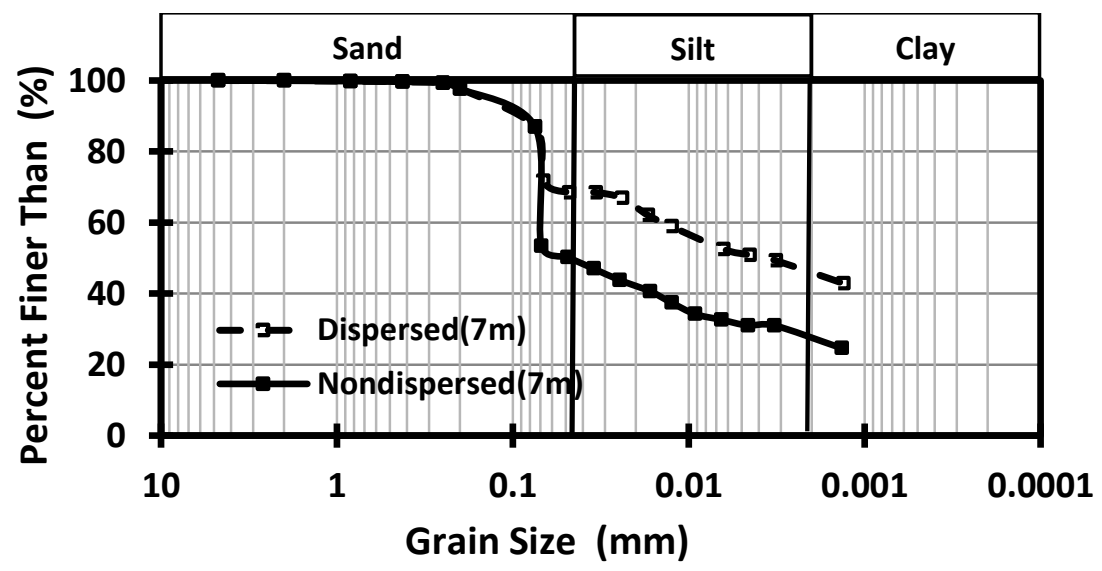

Figure 3 Particle size distribution (dispersed and non-dispersed) of the MFT sample collected at a depth of $7 \mathrm{~m}$ from Standpipe 1 


\subsubsection{Clay fraction by methylene blue}

The quantity of exposed clay mineral in the sample can be estimated using an empirical relationship developed for oil sands tailings:

$$
\text { Clay mineral fraction }(\%)=[(0.006)(\mathrm{MB} \text { value })+0.04] / 0.14
$$

This relationship yields a clay fraction value of $48 \%$ for the bulk MFT sample from Standpipe 1, which is within the range of clay-size values (i.e. $44 \%,<2 \mu \mathrm{m}$ ) extrapolated from the dispersed PSD (Figure 3 ) for the MFT sample collected at a depth of $7 \mathrm{~m}$. It should be noted that the MB test was conducted on a dispersed MFT sample (AGAT Laboratories Ltd.).

\subsection{Soil water characteristic curve}

Figure 4 shows the SWCC for the MFT sample obtained from Standpipe 1, which includes the early data dominated by the sedimentation process ( 0.01 to $10 \mathrm{kPa}$ ) as well as the drying SWCC (i.e. 10 to $320 \mathrm{kPa}$ ) for the MFT sample collected at a depth of $7 \mathrm{~m}$. The SWCC is the relationship between the amount of water in the MFT specimen and various applied soil suctions. The change in gravimetric water content (GWC) defines the water storage function as suction changes (Fredlund et al., 2011). Usually, excess water is removed from the cell prior to the test. In this procedure, the MFT inside the Tempe cell would initially (generally) settle to a void ratio similar to that obtained from settling tests.

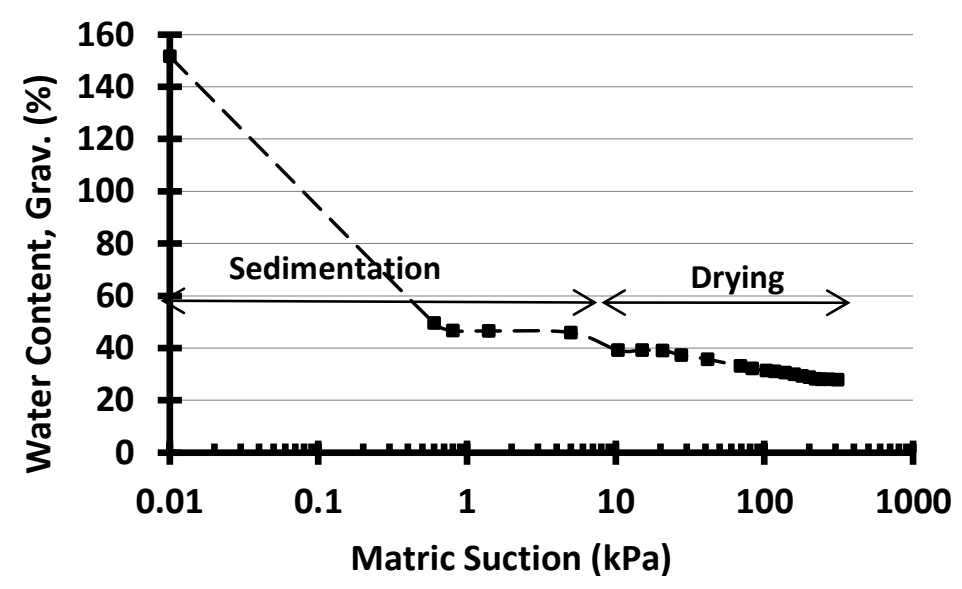

Figure 4 Soil water characteristic curve of the gravimetric water content versus suction for the MFT sample collected at a depth of $7 \mathrm{~m}$ from Standpipe 1

The early portion of the curve (i.e. from 0.01 to $6 \mathrm{kPa}$ ) shows that the MFT slurry inside the Tempe cell is undergoing hindered sedimentation. Eventually the MFT settles under self-weight consolidation to a GWC of about $40 \%$ at $6 \mathrm{kPa}$. The sedimentation process at $0.6 \mathrm{kPa}$ is depicted in Figure 5 .

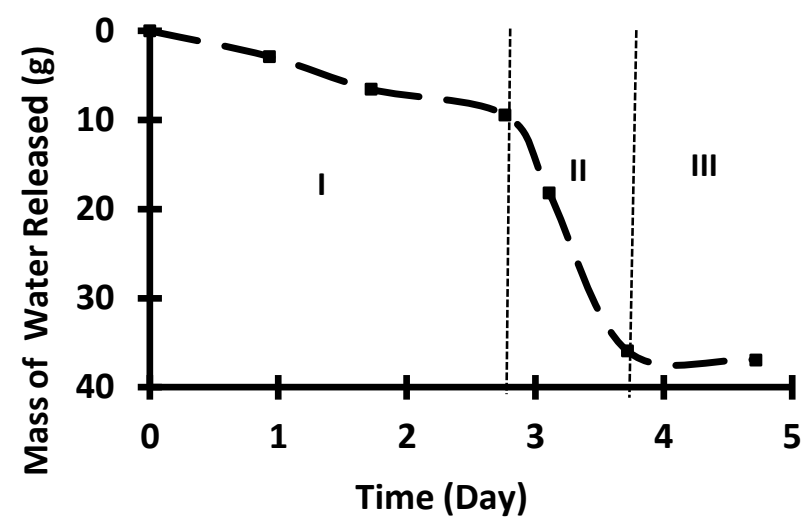

Figure 5 Settling process of MFT inside the Tempe cell at applied suction of $0.6 \mathrm{kPa}$ 
Figure 5 shows that the settling MFT mass inside the Tempe cell went through three different stages similar to those observed in settling tests: a slow decreasing (constant) rate period (from start to Day 3), a falling rate period (from Day 3 to Day 4) and a constant rate period (from Day 4 onward). At the end of the settling process and prior to the onset of the drying process, a large amount of water ( $\sim 35 \mathrm{~g}$ ) was removed from the sample.

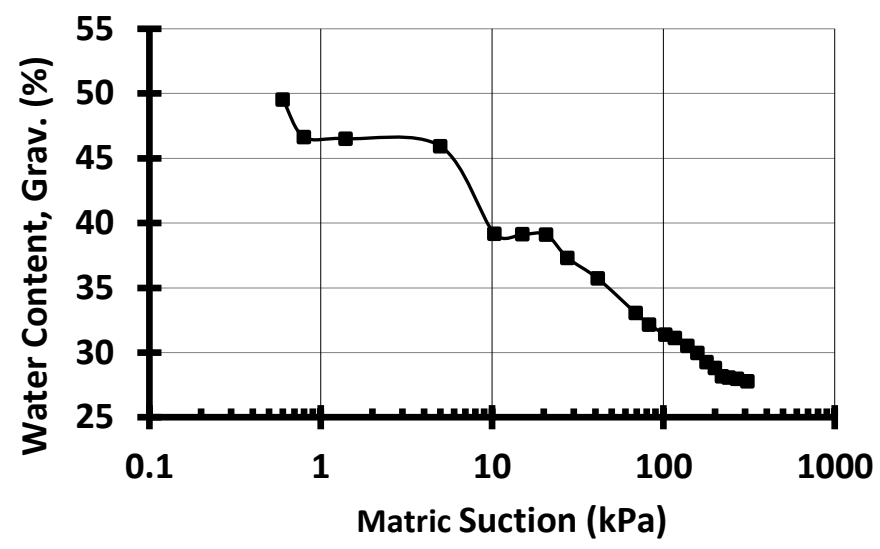

Figure 6 Portion of the soil water characteristic curve for the MFT without the initial water content

Figure 6 shows the dewatering process of MFT SWCC with the initial water content for better visualisation (i.e. from 0.6 to $320 \mathrm{kPa}$ ). The curve shows multiple breaks during the dewatering of the MFT. The curvatures that occur in the settling region for an initially high-water-content MFT specimen should not be taken to represent the air entry value (AEV) of the SWCC (Fredlund et al., 2011). The portion of the SWCC following the MFT settling (i.e. from $20 \mathrm{kPa}$ onward) also shows no curvature or break associated with the AEV of the MFT tested. This suggests that the silt-clay MFT has an AEV beyond the suction range tested in this study (i.e. $\mathrm{m}>320 \mathrm{kPa}$ ).

Figure 7 shows that the void ratio changes as a function of matric suction obtained from the SWCC data. This relationship also represents the shrinkage curve in terms of suction. It should be noted that the initial data point starts at a void ratio of approximately 4 , which is not plotted on this curve. It is assumed that before the drying process the void ratio will change due to settling and should be determined from settling curves. After settling, the void ratio is assumed to change due to shrinkage. The void ratio changes rapidly with increasing matric suction and becomes almost constant at matric suctions $>100 \mathrm{kPa}$.

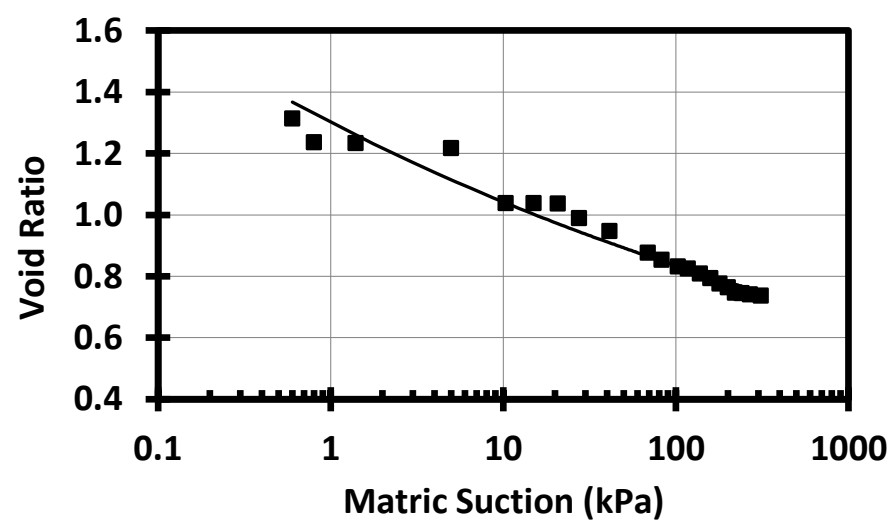

Figure 7 Change in void ratio versus suction obtained from the soil water characteristic curve of the MFT sample collected at a depth of $7 \mathrm{~m}$ from Standpipe 1 


\subsection{Evaporation tests}

Figure 8 shows normalised evaporation, $\mathrm{AE} / \mathrm{PE}$, as a function of drying time for the sample collected at a depth of $7 \mathrm{~m}$ from Standpipe 1 with a solids content of $41 \%$. AE is actual evaporation, and PE is potential evaporation. Time zero in Figure 8 corresponds to a nearly saturated state (or a high water availability).

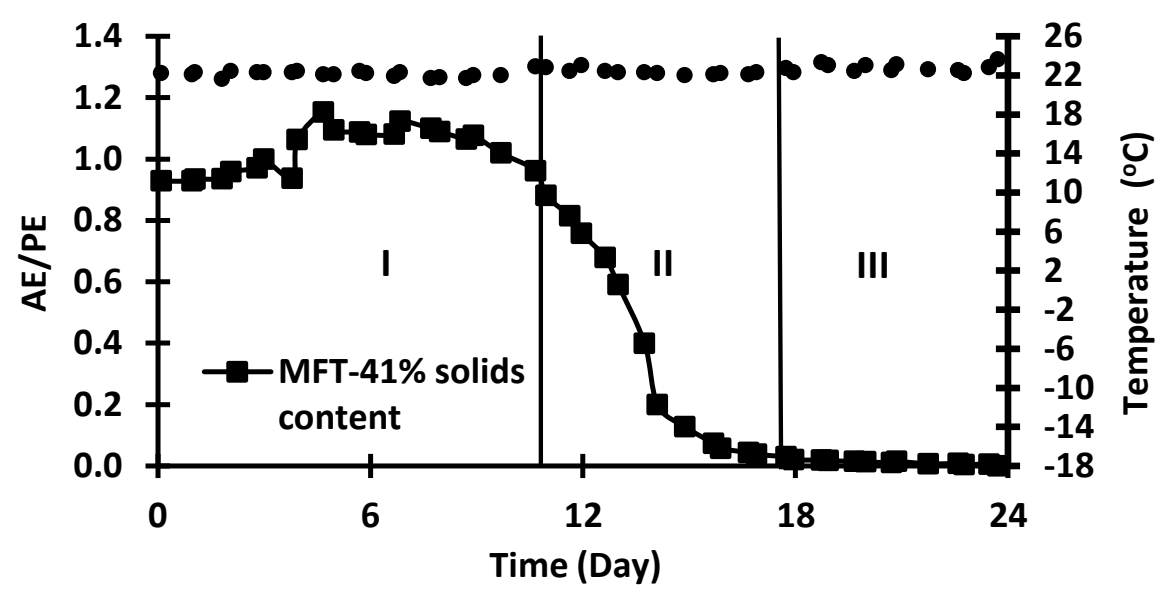

Figure 8 The ratio, $A E / P E$, of actual evaporation and potential evaporation versus drying time for the MFT sample collected at a depth of $7 \mathrm{~m}$ from Standpipe 1

The curve presented in Figure 8 exhibits three drying stages:

- Stage I (Day 0 to Day 10): an initial constant-rate drying stage that occurs early in the process while the MFT is wet and conductive enough to supply water to the site of evaporation at the rate commensurate with the evaporative demand. During this stage, the evaporation rate is limited by, and hence controlled by, external meteorological conditions (weather-controlled) rather than the properties of the MFT profile.

- Stage II (Day 10 to Day 16): an intermediate falling drying stage during which the evaporation rate falls progressively below the potential evaporation. At this stage, the evaporation rate is controlled or dictated by the rate at which the gradual drying MFT profile can deliver water towards the evaporation zone.

- Stage III (Day 16 onward): a residual slow-rate drying stage that is established eventually may persist at nearly steady rate for many days, weeks or months. At this stage, the surface-zone has become desiccated.

The AE/PE ratio is approximately 1 at the start of the evaporation test (Stage I) and becomes slightly greater than 1 as the water surface continues to evaporate. This deviation occurs in most oil sands FFT containing bitumen residual. Wilson et al. (1997) attributed the deviation for the Beaver Creek sand to slight variations in the aerodynamic resistance in the air space above the water and soil evaporation pans as well as the surface temperatures at the time of the tests. The MFT continues to evaporate at a near potential rate and then begins to decline (Stage II). The AE/PE ratio falls to near zero after approximately Day 29 of the test period, when the MFT reaches air-dry state. In summary, it takes approximately three weeks for MFT with $41 \%$ solids content and a thickness of $5 \mathrm{~cm}$ to become desiccated and dry.

Figure 9 shows the plot of the AE/PE ratio versus total suction for the MFT computed using the equation given by Wilson et al. (1997): 


$$
\frac{A E}{P E}=\left[\frac{\exp \left(\frac{\Psi g W}{R T}\right)-h_{a}}{1-h_{a}}\right]
$$

Where:

ha $=$ the relative humidity of the air above the evaporating soil and water surface.

$\psi=$ the total suction in the liquid water phase expressed as equivalent matric suction and as a negative value.

$\mathrm{W}=$ the molecular weight of water $(0.018 \mathrm{~kg} / \mathrm{mol})$.

$\mathrm{g} \quad=$ acceleration $\left(\mathrm{m} / \mathrm{s}^{2}\right)$.

The average measured $h_{a}$ value of $27 \%$ was used in the calculations. Values of $A E / P E>1$ were set to 1 , as the equation was designed for a maximum value of $h_{a}$ equals to $1(100 \%)$.

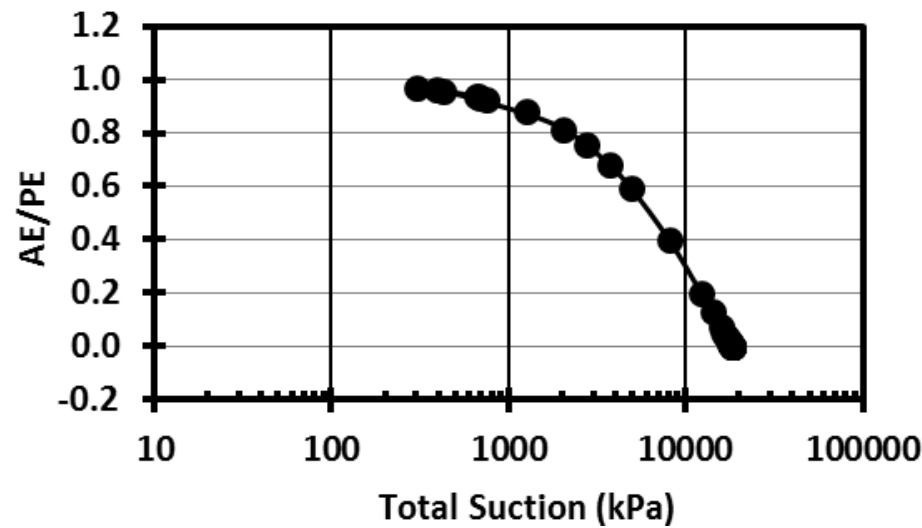

Figure 9 The ratio, AE/PE, of actual evaporation and potential evaporation versus total suction for the MFT sample collected at a depth of $7 \mathrm{~m}$ from Standpipe 1

The correlation shown in Figure 9 is independent of time, water content and texture. The AE/PE ratio is approximately constant and close to 1 for values of total suction up to $3,000 \mathrm{kPa}$. The actual rate of evaporation begins to decline sharply once the value of total suction exceeds $3,000 \mathrm{kPa}$. The AE/PE ratio falls to near zero at a value of total suction equal to approximately $20,000 \mathrm{kPa}$. This point of evaporation is controlled by the relative humidity in the air (Wilson et al., 1997). Soil evaporation should cease when the relative humidity in the soil reaches equilibrium with the relative humidity of the air above the soil.

\subsection{Effect of solids content and bitumen on the rate of evaporation of the MFT}

Figure 10 shows the comparison between the drying curve of the MFT sample with $41 \%$ solids content collected at a depth of $7 \mathrm{~m}$ and the MFT diluted to $26 \%$ solids content, which is approximately equal to the initial solids content of the MFT prior to placement into the $10 \mathrm{~m}$ standpipe in 1982. 


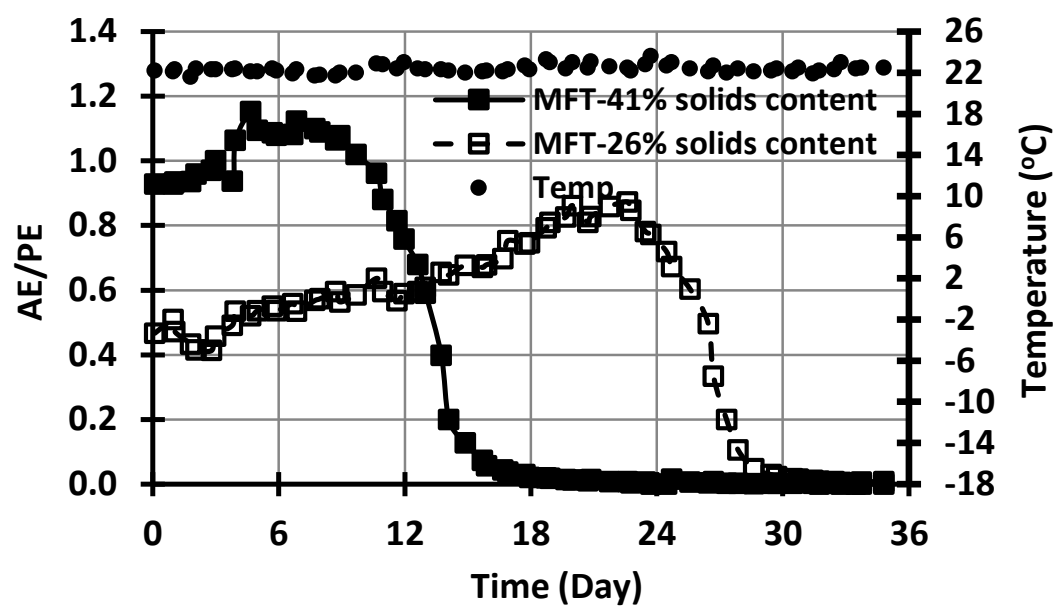

Figure 10 The ratio, $\mathrm{AE} / \mathrm{PE}$, of actual evaporation and potential evaporation versus drying time for the MFT samples ( $41 \%$ and $26 \%$ solids contents) collected at a depth of $7 \mathrm{~m}$ from Standpipe 1

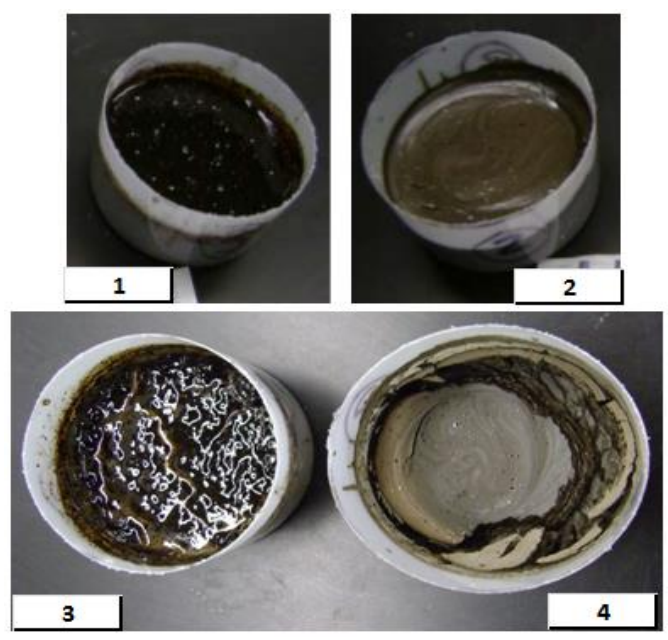

Figure 11 Measurement of evaporation from lysimeters $(300 \mathrm{~mm}$ in diameter $\times 200 \mathrm{~mm}$ in height) containing MFT with $26 \%$ solids content (images 1 and 3 ) and MFT with $41 \%$ solids content (images 2 and 4 ) from samples collected at a depth of $7 \mathrm{~m}$ from Standpipe 1

As stated previously, bitumen exists in the tailings both as free and adsorbed bitumen. In tailings with higher solids content, the bitumen exists as adsorbed bitumen and may be considered to be part of or bonded to the solids (i.e. Figure 11, photographs 2 and 4). However, in tailings with a lower solids content, the bitumen exists in the tailings porewater as free bitumen and forms a film on the surface of the tailings as evaporation progresses (i.e. Figure 11, photographs 1 and 3). This film behaves similarly to a latex paint surface that limits further drying from deeper layers and thus reduces the actual evaporation. During Stage I drying, the AE/PE ratio of the MFT with lower solids content remains initially lower (close to 0.5 ) and then starts to increase to its highest value of approximately 0.9 after Day 23 at the onset of Stage II. Meanwhile, the $A E / P E$ ratio for the higher solids content remains higher (i.e. 0.8-1.1) initially and starts to decline gradually during Stage II and reaches its lowest value (close to zero) after Day 15. The lower solids content MFT eventually reaches its residual water content after Day 33. In summary, the MFT with the higher solids content (i.e. 41\%) dewatered under atmospheric drying at a much faster rate than that for MFT with the lower initial solids content of $26 \%$. This is attributed to the free residual bitumen in the porewater of the MFT. 


\subsection{Comparison of evaporation rates between untreated and treated MFT}

Figure 12 shows the drying curves for untreated MFT from Standpipe 1 and treated MFT tested with the same thickness. However, the amount of bitumen varies in each sample. In these tests, the untreated MFT from Standpipe 1 was diluted to $30 \%$ solids content (from $41 \%$ ), and both the undiluted and diluted samples were compared to three treated samples: flocculated thickened tailings with $49 \%$ solids content, TT plus $1 \%$ flyash and in-line flocculated MFT with $32 \%$ solids content.

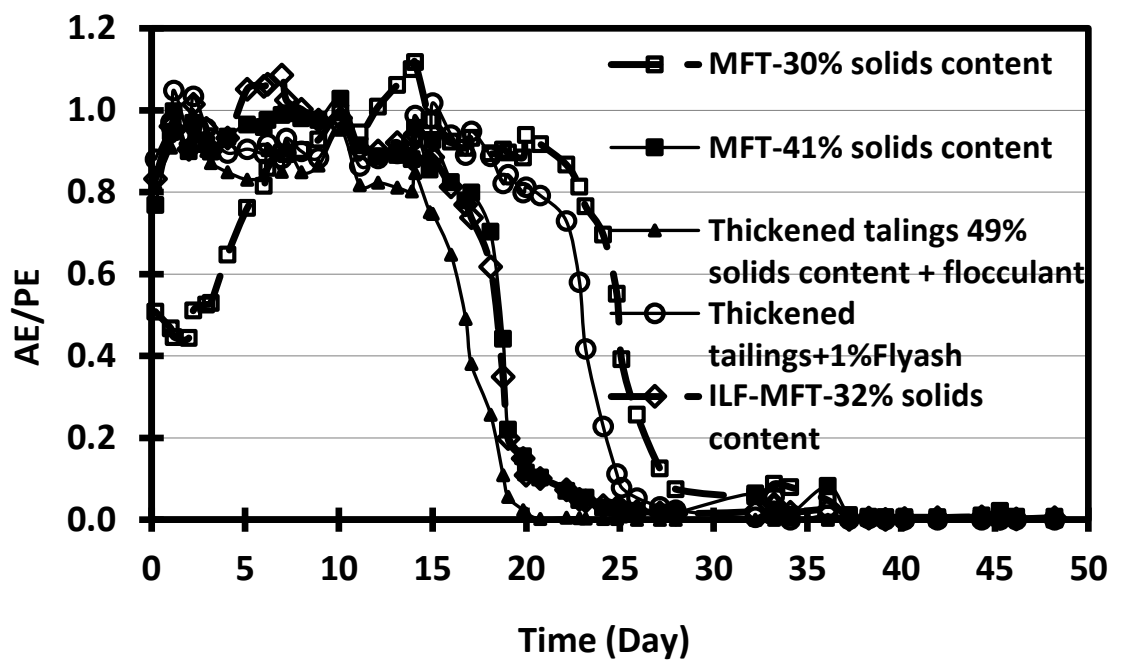

Figure 12 The ratio, $A E / P E$, of actual evaporation and potential evaporation versus drying time for the MFT samples collected at a depth of $7 \mathrm{~m}$ from Standpipe 1 and three treated samples: flocculated thickened tailings with $49 \%$ solids content, TT plus $1 \%$ flyash and in-line flocculated MFT with $32 \%$ solids content

A comparison between untreated and treated samples indicates that the treated $\Pi T$ with high solids content (49\%) evaporates at a higher rate and dewaters faster than the untreated MFT with $30 \%$ solids content. Results also show that the treated MFT with $32 \%$ solids content (ILF-MFT) evaporates at the same rate as the untreated MFT with $41 \%$ solids content. It is also noted that both treated TT with flyash and untreated MFT with lower solids content (30\%) have a slower rate of evaporation. In other tests, it has been shown that the effect of flyash on the evaporation rate depends on the type and amount of flyash used. In summary, results show that the solids content has a significant effect on the actual evaporation rate of MFT. In addition, the bitumen content also has a significant effect on the actual evaporation rate of MFT with low solids content.

\section{$4 \quad$ Summary and observations}

Results indicate that the standpipe MFT is mainly clay/silt with a small amount of sand. The solids and bitumen contents measured at a depth of $7 \mathrm{~m}$ are $41 \%$ and $2.6 \%$, respectively. The initial solids content prior to placement of the MFT into the standpipe (in 1982) was about 31\%; therefore, there was an increase in solids content of about $10 \%$ at a depth of $7 \mathrm{~m}$. Results show that the MFT with $41 \%$ solids content evaporates much faster (1.8 times faster) compared with those with $26 \%$ and $30 \%$ solids contents with the same amount of bitumen ( $3 \%)$. This is attributed to free bitumen in the porewater associated with the lower solids content in the MFT. It was noted that at low solids content, the bitumen forms a film on the surface that significantly reduces the actual rate of evaporation during the early stages of atmospheric drying. At higher solids content and with the addition of flocculant to the MFT, the bitumen becomes adsorbed in the solid phase of the MFT and has less effect on the actual evaporation rate.

The results of this study are of value to the oil sands industry for the dewatering of MFT for mine closure. The oil sands industry is currently conducting a wide range of field tests as well as commercial-scale trials 
aimed at dewatering FFT deposits using atmospheric drying. The global objective is to develop methods of dewatering to increase undrained shear strength of the sediments, thereby allowing capping and closure of the deposits.

\section{Acknowledgements}

Funding for the Standpipe Decommissioning Project was provided by the Oil Sands Tailings Consortium. Thank you to Steve Gamble and Christine Herygers who assisted in the sampling programme and to Vivian Giang who assisted in the editing and final preparation of this paper.

\section{References}

Fredlund, D.G., Stone, J. and Stianson, J. (2011) Determination of water storage and permeability functions for oil sands tailings, in Proceedings $15^{\text {th }}$ International Conference on Tailings and Mine Waste, Norman B. Keevil Institute of Mining Engineering, University of British Columbia, Vancouver, BC, Canada, 6-9 November, 2011, pp. 315-328.

Jeeravipoolvarn, S., Scott, J.D. and Chalaturnyk, R.J. (2009) 10-m standpipe tests on oil sand tailings: long-term experimental results and prediction, Canadian Geotechnical Journal, Vol. 46, pp. 875-888.

Wilson, G.W., Fredlund, D.G. and Babour, S.L. (1997) The effect of soil suction on evaporative fluxes from soil surfaces, Canadian Geotechnical Journal, Vol. 34, pp. 145-155.

Wilson, G.W., Kabwe, L.K., Donahue, R. and Lahaie, R. (2011) Field performance of in-line flocculated fluid fine tailings using thin lift deposition, in Proceedings Sixth International Conference on Mine Closure (Mine Closure 2011), A.B. Fourie, M. Tibbett and A. Beersing (eds), 19-21 September 2011, Lake Louise, Canada, Australian Centre for Geomechanics, Perth, Vol. 1, pp. 473-479. 